\title{
A Coupled Experimental/Numerical Approach for Tuning High-performing SOFC-Cathode
}

\author{
Özden Çelikbilek ${ }^{\mathrm{ab}}$, David Jauffres ${ }^{\mathrm{b}}$, Laurent Dessemond ${ }^{\mathrm{a}}$, Mónica Burriel ${ }^{\mathrm{c}}$, \\ Christophe L. Martin ${ }^{b}$, and Elisabeth Djurado ${ }^{a}$ \\ aUniv. Grenoble Alpes, CNRS, LEPMI, F-38000 Grenoble, France \\ ${ }^{\mathrm{b} U n i v . ~ G r e n o b l e ~ A l p e s, ~ C N R S, ~ S I M A P, ~ F-38000 ~ G r e n o b l e, ~ F r a n c e ~}$ \\ ${ }^{c}$ Univ. Grenoble Alpes, CNRS, LMGP, F-38000 Grenoble, France
}

In this paper, a coupled experimental and numerical approach is used to assess the influence of electrode micro/nano-structure and composition on electrochemical performance. First, the areaspecific resistance (ASR $\left.{ }_{\text {chem }}\right)$ of 100 vol. \% $\mathrm{La}_{0.6} \mathrm{Sr}_{0.4} \mathrm{Co}_{0.2} \mathrm{Fe}_{0.8} \mathrm{O}_{3-\delta}$ (LSCF) and 60:40 vol. \% LSCF:CGO $\left(\mathrm{Ce}_{0.9} \mathrm{Gd}_{0.1} \mathrm{O}_{2-\delta}\right)$ composite cathode operating at intermediate temperature range $\left(550-650{ }^{\circ} \mathrm{C}\right)$ was investigated by impedance spectroscopy. Despite positive expectations based on the literature, the composite in this work showed $\mathrm{ASR}_{\text {chem }}$ values almost twice as high as those of the pure LSCF cathode. It is believed that the beneficial effect of the addition of CGO on the bulk transport is lost by a drastic reduction of the specific surface area. Next, a 3D finite element method (FEM) cube model is implemented to study the influence of the CGO addition and to relate microstructural modifications to the $\mathrm{ASR}_{\text {chem. }}$. The model successfully calculates the performance of randomly-distributed constituent phases.

\section{Introduction}

Solid oxide fuel cell (SOFC) technology offers a promising choice for a clean, efficient and cost effective power generation. Lowering the operation temperature down to 500$700{ }^{\circ} \mathrm{C}$ brings several interesting positive effects. It allows a broader set of materials to be used. It reduces stability and chemical compatibility issues of the interconnect and cell materials. Finally it results in less degradation of the cell and helps in faster start-up (1). All these advantages lead to efficiencies in cost and attainable power. However, the electrochemical kinetics of SOFC components are relatively slow at low operating temperatures (2). Attention has been particularly given to the oxygen reduction reaction (ORR) mechanisms in the cathode since it causes one of the major voltage losses within the cell. $\mathrm{La}_{\mathrm{x}} \mathrm{Sr}_{1-\mathrm{x}} \mathrm{Co}_{\mathrm{y}} \mathrm{Fe}_{1-\mathrm{y}} \mathrm{O}_{3-\delta}$ (LSCF) based perovskites have been extensively studied over the past three decades not only for their remarkable mixed ionic and electronic conductivity but also for their high oxygen diffusion and surface exchange coefficients (3-5). The ionic conductivity of LSCF falls in a great extent at temperatures lower than $600{ }^{\circ} \mathrm{C}$, thus restraining the ORRs near the electrode/electrolyte interface (6). Several studies have highlighted the benefit of composite structures where the effective ionic conductivity of the cathode can be enhanced by adding an ionically conducting second phase, such as $\left(\mathrm{CeO}_{2}\right)_{1-\mathrm{x}}\left(\mathrm{Gd}_{2} \mathrm{O}_{3}\right)_{\mathrm{x}}$ into LSCF (7-11). 
Several deposition techniques have been employed to produce cathodes with high porosity and large specific surface in order to reduce polarization losses. Electrostatic spray deposition (ESD) stands out as a promising low cost and parameter-controlled technique (12-14). The grain size, porosity, surface area and film thickness can be tailored to obtain desired films. LSCF films with a large variety of microstructures ranging from dense to highly porous can be obtained by ESD (15). A nano-crystalline and nano-porous columnar-type microstructure is expected to be beneficial to reduce polarization losses thanks to its large active inner surface area. Notably, micro/nanostructure-performance relationships are evidenced by the so called ALS (Adler, Lane and Steele) 1D continuum model (5). Assuming a macrohomogeneous morphology, these authors derived a simple analytical expression to relate the area specific resistance, $\mathrm{ASR}_{\text {chem, }}$, to microstructural parameters for mixed ionic-electronic conductors. However, composite cathodes and/or inhomogeneous microstructural features are not taken into account in the model.

In this paper, high-performing 100 vol. \% $\mathrm{La}_{0.6} \mathrm{Sr}_{0.4} \mathrm{Co}_{0.2} \mathrm{Fe}_{0.8} \mathrm{O}_{3-\delta}$ (LSCF) and 60:40 vol. \% LSCF:CGO $\left(\mathrm{Ce}_{0.9} \mathrm{Gd}_{0.1} \mathrm{O}_{2-\delta}\right)$ composite cathodes were deposited by ESD and screen-printing (SP). To assess and quantify the effect of ionically conducting CGO phase in LSCF, 3D Finite Element Method (3D FEM) simulations (16-18) were performed. Thanks to this model, the changes in the nano-scale architecture of the electrode during processing or long-term operation can be simulated. The films were characterized by Scanning Electron Microscopy (SEM). The electrochemical properties were measured by Electrochemical Impedance Spectroscopy (EIS).

\section{Experimental}

\section{$\underline{\text { Film Deposition }}$}

100 vol.\% LSCF, 60:40 vol.\% LSCF:CGO solutions (referred to as 100 LSCF and 60:40 LSCF:CGO, respectively) were deposited on CGO substrates using a vertical ESD setup (19). The substrate holder was mechanically moved in $\mathrm{x}$ and $\mathrm{y}$ directions with a rate of $1 \mathrm{~mm} \mathrm{~s}^{-1}$. The precursor solutions of $\mathrm{La}_{0.6} \mathrm{Sr}_{0.4} \mathrm{Co}_{0.2} \mathrm{Fe}_{0.8} \mathrm{O}_{3-\delta}$ were prepared by dissolving $\mathrm{La}\left(\mathrm{NO}_{3}\right)_{3} \cdot 6 \mathrm{H}_{2} \mathrm{O}$ (Prolabo, 99.99\%), $\mathrm{SrCl}_{2} \cdot 6 \mathrm{H}_{2} \mathrm{O}$ (Strem Chemicals, 99\%), $\mathrm{Co}\left(\mathrm{NO}_{3}\right)_{2} \cdot 6 \mathrm{H}_{2} \mathrm{O}$ (Sigma-Aldrich, 99.999\%) and $\mathrm{Fe}\left(\mathrm{NO}_{3}\right)_{2} .9 \mathrm{H}_{2} \mathrm{O}$ (Sigma-Aldrich, $99.99 \%$ ) salts in adequate amounts to obtain the desired stoichiometry. These were mixed in ethanol and butyl carbitol with a 1:2 volume ratio and a total salt concentration of 0.02 mol L ${ }^{-1}$. The $\mathrm{C}_{0.9} \mathrm{Gd}_{0.1} \mathrm{O}_{2-\delta}$ solutions were prepared similarly by dissolving cerium nitrate hexahydrate $\left(\mathrm{Ce}\left(\mathrm{NO}_{3}\right)_{3} \cdot 6 \mathrm{H}_{2} \mathrm{O}\right.$, Rectapur Prolabo, $\left.99.5 \%\right)$ and gadolinium nitrate $\left(\mathrm{Gd}\left(\mathrm{NO}_{3}\right)_{3} \cdot 6 \mathrm{H}_{2} \mathrm{O}\right.$, Aldrich, $\left.99.99 \%\right)$ in 1:4 volume ratio of ethanol and butyl carbitol with total salt concentration of $0.02 \mathrm{~mol} . \mathrm{L}^{-1}$. The solutions were atomized using a high voltage 5-6 kV maintaining a cone-jet atomization regime for $3 \mathrm{~h}$ at a substrate temperature, a nozzle to substrate distance and a flow rate of $300{ }^{\circ} \mathrm{C}, 15 \mathrm{~mm}$ and 1.5 $\mathrm{mLh}^{-1}$ respectively (Table I). These ESD deposition conditions were optimized in order to obtain a columnar type microstructure. After the ESD deposition, the films were sintered at $800^{\circ} \mathrm{C}$ for $2 \mathrm{~h}$ in air using heating and cooling rates of $2^{\circ} \mathrm{C} \mathrm{min}{ }^{-1}$ and $3^{\circ} \mathrm{C} \mathrm{min}{ }^{-1}$, respectively. 
TABLE I. ESD Deposition Conditions for a Columnar Type Microstructure.

\begin{tabular}{cccccc}
\hline $\mathbf{T},{ }^{\circ} \mathbf{C}$ & $\mathbf{Q}, \mathbf{~ m L ~ h}^{-1}$ & $\mathbf{d}, \mathbf{m m}$ & $\mathbf{t}, \mathbf{h}$ & $\mathbf{V}, \mathbf{k V}$ & $\begin{array}{c}\text { Film } \\
\text { thickness, } \boldsymbol{\mu m}\end{array}$ \\
\hline 300 & 1.5 & 15 & 3 & $5-6$ & 10 \\
\hline
\end{tabular}

To maximize the contact area between the electrode surface and the current collectors, $\mathrm{La}_{0.62} \mathrm{Sr}_{0.38} \mathrm{Co}_{0.19} \mathrm{Fe}_{0.8} \mathrm{O}_{3-\delta}$ powder (Marion Tech. $\mathrm{d} 50=0.27 \mu \mathrm{m}$ ) was mixed with an organic binder (50 wt. \%) (Zschimmer and Schwarz, KD2921). Then, it was screen printed (SP) symmetrically onto ESD deposited films to serve as a current collecting layer (CCL). The films were heated in an oven below $700{ }^{\circ} \mathrm{C}$ to eliminate the solvents and binders of the ink.

\section{Material Characterization}

The microstructures analysis of the deposited films were studied using scanning electron microscopy, with field emission gun, FEG-SEM (ZEISS Ultra 55).

\section{Electrochemical Characterization}

Impedance spectroscopy measurements were performed on symmetrical cells. Platinum grids (Heraeus, 3600 meshes. $\mathrm{cm}^{-2}$ ) were used as current collectors. The electrochemical characterization was carried out between 550 and $650{ }^{\circ} \mathrm{C}$ in air at open circuit potential (OCP) using an Autolab frequency response analyzer within the frequency range $0.05 \mathrm{~Hz}-10 \mathrm{kHz}$. The amplitude of the measuring signal was set to 20 $\mathrm{mV}$ to ensure the linearity of the electrical response. The magnitude of the total polarization resistance, $\mathrm{ASR}_{\mathrm{pol}}$, is calculated by subtracting the high frequency intercept of the electrode impedance from the low frequency one in the Nyquist plane. The diagrams are normalized to the electrode area $\left(1.54 \mathrm{~cm}^{2}\right)$ and divided by two to account for the electrodes in both sides of a symmetric cell.

\section{Results and Discussion}

\section{Film Microstructure Characterization}

100 LSCF and 60:40 LSCF:CGO composite films composed of ESD and SP layers are shown in Figure 1. A $10 \mu \mathrm{m}$ thick columnar-type ESD layer is topped by a $25-30 \mu \mathrm{m}$ thick SP layer in both cases. Macro pore channels within the ESD layer are 1-3 $\mu \mathrm{m}$ wide. The distinction between the ESD layer and the SP current collecting layer is easily made due to their different micro-nano/structure (Figure 1c, Fig.1g). The submicronic particles of LSCF powder used in the SP deposition provide high porosity. Thus, supplying oxygen gas molecules to the ESD layer is rather facile. We can observe penetration of the SP layer into the macro-pore channels up to $2 \mu \mathrm{m}$ from the electrolyte-electrode interface. The SP layer provides a flat surface which is beneficial for a good contact with the Pt grid for the electrochemical measurements. A remarkable change in the nanostructure of ESD films is observed when CGO is added to LSCF, as shown in Fig. 1d and Fig. 1h. The 60:40 LSCF:CGO composite film exhibits rather dense columns compared to the pure LSCF film that presents a large amount of nano-structured porosity within its columns. Comparing the SEM micrographs to literature data of similarly processed LSCF 
columnar-like microstructures (12), the internal pore structure of LSCF in this work seems more pronounced. The importance of the internal nano-structured porosity has been put into evidence by Dieterle et al. in nanocrystalline $\mathrm{La}_{0.6} \mathrm{Sr}_{0.4} \mathrm{CoO}_{3-\delta}$ (LSC) thin films (20). For a similar grain size $(\sim 28 \pm 10 \mathrm{~nm})$ but larger porosity, a 2.5 fold lower polarization resistance was obtained for a sample calcined at $700{ }^{\circ} \mathrm{C}$ in comparison to one calcined at $800{ }^{\circ} \mathrm{C}$ for $100 \mathrm{~h}$. An increase of porosity clearly enhances the available active surface area for the electrochemical cathodic reaction.

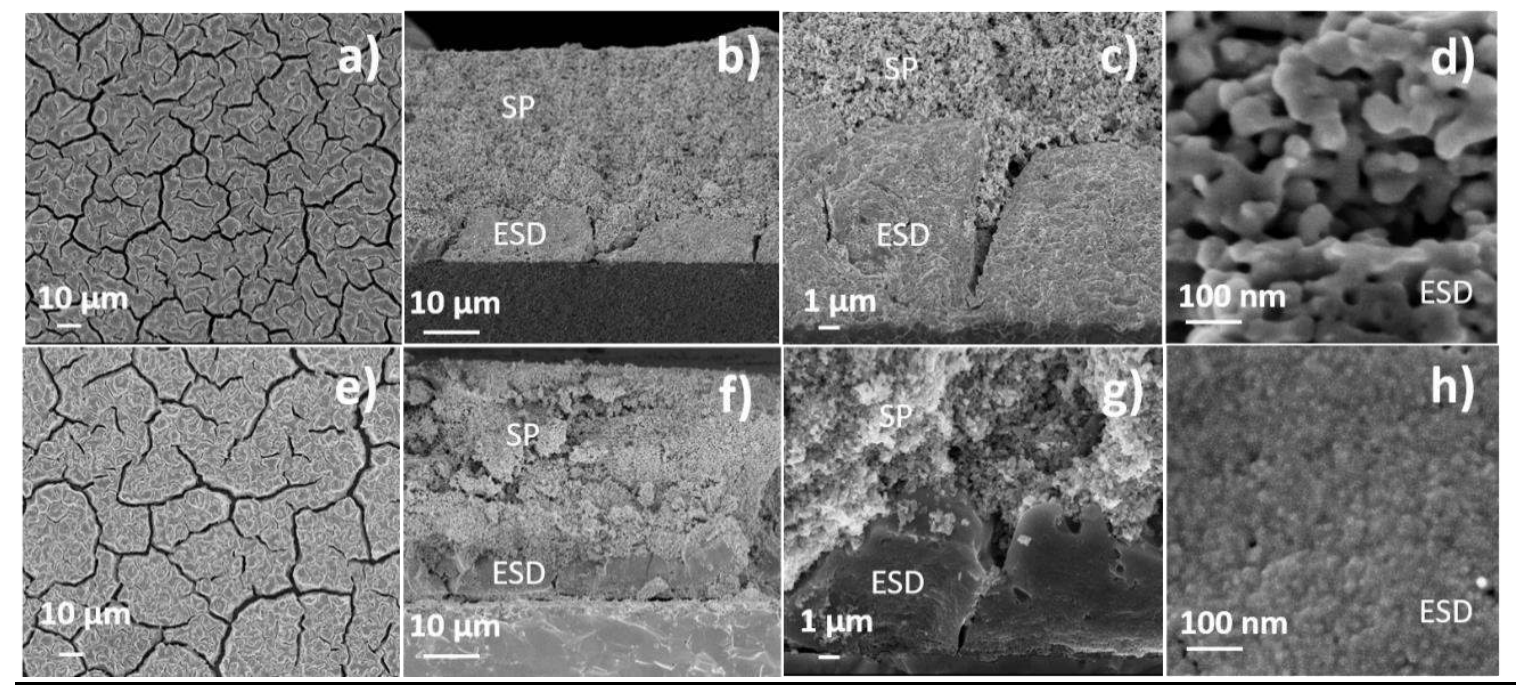

Figure 1. 100 LSCF film: a) top view of ESD film before SP deposition, (b-c) crosssectional views of double-layered films(ESD+SP) and d) zoom of the ESD film crosssection; 60:40 LSCF:CGO composite film: e) top view of ESD film before SP deposition, (f-g) cross-sectional views of double-layered films(ESD+SP) and h) zoom of the ESD film cross-section.

\section{Electrochemical Characterization}

The impedance diagrams of 100 LSCF and 60:40 LSCF:CGO composite films recorded at $550{ }^{\circ} \mathrm{C}$ at $\mathrm{OCP}$ are presented on a Nyquist plot (Figure 2). The series resistance, including the ohmic resistance of the CGO pellet, has been subtracted for an easy comparison of polarization resistance for investigated electrodes. High frequency inductive effects have been experimentally evidenced at temperatures higher than $500{ }^{\circ} \mathrm{C}$. For the investigated temperatures, the electrode reaction mechanism remains nearly unchanged for $100 \mathrm{LSCF}$ and the corresponding composite cathode since the frequency distribution of the electrode impedance is not modified by adding CGO (Figure 2). The experimental diagrams are composed of at least two elementary contributions. These include chemical processes occurring at the cathode, $\mathrm{ASR}_{\text {chem }}$, at high frequencies and gas diffusion limitations $\mathrm{ASR}_{\text {gas }}$ at low frequencies (12). The latter contribution is not thermally activated and is observed as a separate arc only above $550{ }^{\circ} \mathrm{C}(21)$. It originates from the gas phase diffusion through the pores of the electrode $(22,23)$. The associated capacitance of the first arc for both films $\left(10^{-3} \sim 10^{-2} \mathrm{~F} \mathrm{~cm}^{-2}\right)$ implies bulk oxygen transport and surface exchange processes. 


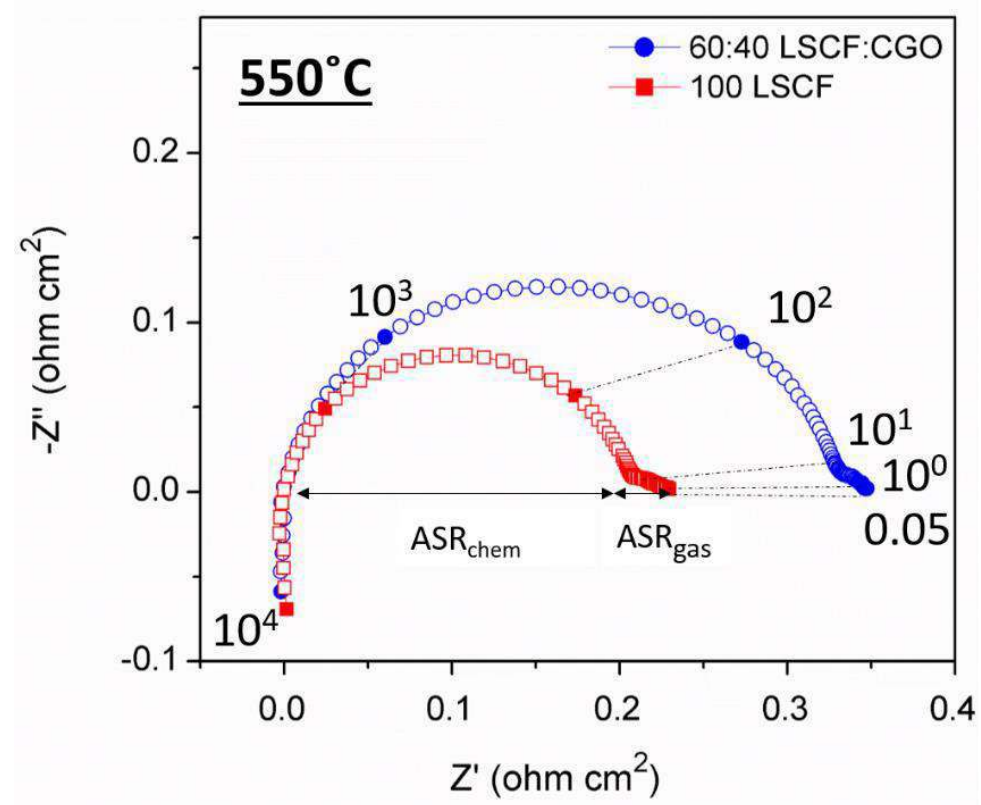

Figure 2. Nyquist plots of electrode impedances recorded at $\mathrm{OCP}$ and at $550^{\circ} \mathrm{C}$.

Table II summarizes the temperature dependence of the total polarization resistance $\left(\mathrm{ASR}_{\mathrm{pol}}=\mathrm{ASR}_{\text {chem }}+\mathrm{ASR}_{\mathrm{gas}}\right)$ of pure LSCF and the LSCF:CGO composite.

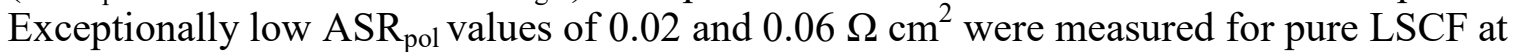
650 and $600{ }^{\circ} \mathrm{C}$, respectively. To the best of our knowledge, these are amongst the lowest reported values for LSCF in 6428 composition measured in OCP conditions $(12,13)$. Given the fact that the electrode microstructure has a profound influence on the electrochemical performance (2), it is worth to compare the electrodes processed and deposited in the same way. The total polarization resistance of LSCF double layer electrodes (ESD+SP) reported by Hsu et al. (13) is $0.05 \Omega \mathrm{cm}^{2}$ and that of Marinha et al. (12) is $0.126 \Omega \mathrm{cm}^{2}$ at $600{ }^{\circ} \mathrm{C}$. The results in this study are closer to Hsu et al.'s values and almost twice lower than the ones reported by Marinha et al. A decrease of sintering temperature from $900{ }^{\circ} \mathrm{C}(12)$ to $800{ }^{\circ} \mathrm{C}$ (this study and ref. (13)) clearly leads to an enhancement of the available active surface area for the oxygen reduction reaction. This demonstrates that the porosity content of the LSCF films prepared by ESD can be tailored by adequate annealing temperatures. Based on SEM image analysis (using ImageJ from the top view of Figure 1a, Figure 1e) $10-15 \%$ porosity arising from macro-pore channels was estimated in the ESD layer. In addition, SEM images (Fig. 1c and Fig. 1d) clearly show that pure LSCF columns present a significant amount of inner porosity.

In terms of material choice, the addition of 40 vol. \% CGO results in an increase of about two fold in $\mathrm{ASR}_{\mathrm{pol}}$ in comparison to pure LSCF (Table II), contrary to literature observations. Indeed, improvements by 2 to 10 fold are reported in the literature (7-10) for composite cathodes. In particular, $\mathrm{ASR}_{\text {chem }}$ of the LSCF:CGO composites were found lower than for pure LSCF between 500 to $700{ }^{\circ} \mathrm{C}$. The common point emerging from these studies seems to be the particle sizes of the deposited films being well above the nano-scaled size reported here. Also, no drastic change in microstructure was noticed with the CGO addition. However, the results reported by Beckel et al. (11) are similar to the present ones between 600 and $650{ }^{\circ} \mathrm{C}$ (Table II). At $650{ }^{\circ} \mathrm{C}$ the authors observed a slightly lower ASR value for pure LSCF in comparison to the composite. The investigated LSCF films exhibit slightly larger particles $(65 \pm 15 \mathrm{~nm})$ compared to the 
present study. In this work, the addition of CGO to LSCF has suppressed the grain growth of LSCF and thus the LSCF-CGO composite electrode maintained its fine nanostructure with LSCF grain size around $30 \mathrm{~nm}$ (Fig. 1h). However, as shown in SEM micrographs (Fig. 1d, Fig. 1h), with the addition of CGO a simultaneous densification occurs. This fine but denser microstructure of the composite appears to be detrimental for the oxygen reduction process due to a lower specific surface area and leads to a larger polarization resistance.

TABLE II. Area Specific Polarization Losses, $\mathrm{ASR}_{\text {pol }}$, between $550-650{ }^{\circ} \mathrm{C}$.

\begin{tabular}{lccc}
\hline Samples & $\mathbf{6 5 0}^{\circ} \mathbf{C}$ & $\mathbf{6 0 0}^{\circ} \mathbf{C}$ & $\mathbf{5 5 0}^{\circ} \mathbf{C}$ \\
\hline 100 LSCF & 0.02 & 0.06 & 0.23 \\
60:40 LSCF:CGO & 0.04 & 0.13 & 0.35 \\
\hline
\end{tabular}

\section{$\underline{\text { 3D Finite Element Model (3D FEM) }}$}

As discussed in the previous section, addition of an ionic conducting second phase (CGO) to LSCF, to enhance the electrode performance by extending the active thickness, gives rise to significant changes in the volume-specific surface area, nanoporosity fraction, tortuosity and the particle size. It is of great importance to quantify the influence of these micro/nano-structural properties to achieve fine-tuning of the electrode performance for future SOFC cathodes.

First, the proposed 3D FEM model will be validated in comparison to the wellestablished ALS 1D model (5) which assumes a macrohomogeneous geometry and a pure MIEC material. Next, this 3D FEM model will be implemented for the case of an inhomogeneous columnar microstructure to calculate the $\mathrm{ASR}_{\text {chem }}$ of pure LSCF and LSCF:CGO composite.

A previously described 3D FEM model implemented for homogeneously distributed MIEC cubes on CGO electrolyte system $(16,17)$, is adopted. To extend the approach to a composite system, a fraction of the cubes is assigned to CGO in the cathodic compartment. The model includes the following processes as illustrated in Figure 3:

1. Surface exchange process at the surface of LSCF in defined boundaries,

2. Bulk diffusion of reduced oxygen ions within the LSCF lattice,

3. Charge transfer at the LSCF(electrode)/CGO(electrolyte) and LSCF(electrode)/CGO(electrode) interfaces,

4. Ionic conduction in CGO (electrode and electrolyte). 


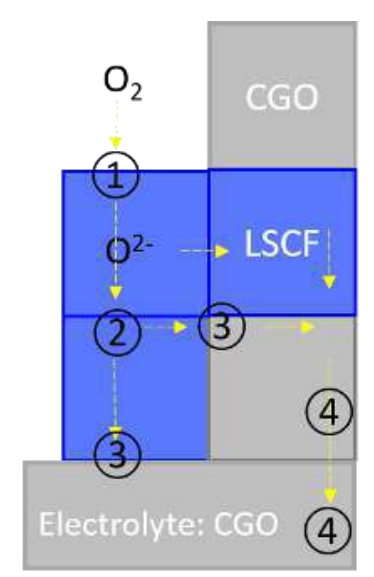

Figure 3. Illustration of the processes in the FEM model for a composite cathode.

COMSOL Multiphysics FEM software was used to solve the two coupled partial differential equations governing bulk $\mathrm{O}^{2-}$ diffusion within LSCF and CGO ionic conduction. A number of assumptions were made in the model. Each individual MIEC particle is assumed to have very high electronic conductivity. Thus, only the ionic current transport contributes to the total resistance. Moreover, any interfacial resistance between the current collector/electrode and counter electrode is neglected and the polarization resistance at the counter electrode is assumed to be zero. As a result, the applied voltage distributes entirely across the electrode and causes a flux of oxide ions through the electrolyte. In addition, the partial pressure of oxygen gas is assumed to be uniform everywhere. These assumptions imply that the behavior of each geometry is representative of the electrode as a whole. Finally, a DC voltage $(100 \mathrm{mV})$ between the current collector and the reversible counter electrode on the other side is applied under steady state conditions and the polarization resistance of the cathode is calculated.

3D FEM Model Verification by 1D ALS Model. The ALS model is based on semiinfinite porous cathodes which uses volume-averaged geometrical parameters and linear irreversible thermodynamics in reaction rates. An analytical expression for the cathode performance, $\mathrm{ASR}_{\mathrm{chem}}$, is given (Eq. 1) and requires some information of the real geometrical parameters that can be obtained for example from synchrotron tomography $(24,25)$ or FIB/SEM techniques $(26,27)$.

$$
\mathrm{ASR}_{\text {chem }}=\frac{\mathrm{RT}}{4 \mathrm{~F}^{2}}\left(\sqrt{\frac{\tau}{(1-\varepsilon) \mathrm{aD}_{\mathrm{o}} \mathrm{k}_{\mathrm{o}} \mathrm{C}_{\mathrm{o}}^{2}}}\right)
$$

where $\mathrm{R}$ is the ideal gas constant $\left(\mathrm{J} \mathrm{K}^{-1} \mathrm{~mol}^{-1}\right), \mathrm{F}$ the Faraday's constant $\left(\mathrm{C} \mathrm{mol}^{-1}\right)$ and $\mathrm{T}$ the temperature $(\mathrm{K}), \tau$ the solid phase tortuosity, $\varepsilon$ the open porosity and a the surface area per unit volume $\left(\mathrm{cm}^{-1}\right), \mathrm{D}_{\mathrm{o}}$ the oxygen self-diffusion coefficient $\left(\mathrm{cm}^{2} \mathrm{~s}^{-1}\right), \mathrm{k}_{\mathrm{o}}$ the oxygen surface exchange coefficient $\left(\mathrm{cm} \mathrm{s}^{-1}\right)$ and $\mathrm{c}_{\mathrm{o}}$ the concentration of oxygen (mol $\mathrm{cm}^{-3}$ ). In this work, a model geometry consisting of randomly distributed cubes of pure MIEC (LSCF) and pore phase on top of the dense electrolyte (CGO) have been generated as depicted in Figure 4. Each cube represents one particle or a void (porosity). The total geometry of the cathode consists of $10 \times 10 \times 25$ cubes in which the length of a cube edge is $400 \mathrm{~nm}$. The required geometrical parameters for Eq.1 are computed on 10 numerically generated cubes with $30 \%$ porosity. The averaged values obtained are 1.3 for tortuosity and $2.98 \mu^{-1}$ for the specific surface area. 


\section{Cube size: $400 \mathrm{~nm}$}

$(10 \times 10 \times 25)$

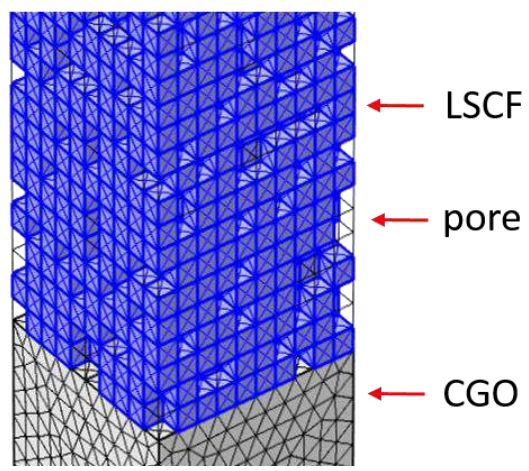

Figure 4. A macrohomogeneous porous MIEC cathode (LSCF) FEM mesh used for comparison with the ALS model.

From the Gerischer-like response observed in the recorded impedance spectra of pure LSCF, the chemical transport parameters $\mathrm{D}^{\delta}$ and $\mathrm{k}^{\delta}$ are extracted. These values are compared with the literature data measured by different techniques (28-31). Tracer oxygen diffusion coefficient, $\mathrm{D}^{*}$, have an activation energy $(1.93 \mathrm{eV})$ similar to the existing data (6). On the other hand, quite high $\mathrm{k}^{*}$ values are found for LSCF films deposited by ESD. The conversion from $D_{o}$ to $D^{*}$ was done using $D^{*}=D_{o} \cdot f_{o}$ equation where $f_{o}$ is the correlation factor for oxygen diffusion in LSCF. For perovskite lattice $f_{o}$ equals to 0.67 . The relationship between the tracer transport $\left(\mathrm{D}^{*}, \mathrm{k}^{*}\right)$ and chemical transport parameters $\left(\mathrm{D}^{\delta}, \mathrm{k}^{\delta}\right)$ is as follows: $\mathrm{D}^{\delta}=\mathrm{D}^{*} \cdot \gamma$ and $\mathrm{k}^{\delta}=\mathrm{k}^{*} \cdot \gamma$. These equations use a thermodynamic enhancement factor, $\gamma$, that can be obtained from oxygen nonstoichiometry measurements of LSCF (Eq. 2)(28). $\mathrm{C}_{\mathrm{o}}$ is related to concentration of oxygen defects, $\mathrm{C}_{\mathrm{mc}}$, in the MIEC. $\mathrm{C}_{\mathrm{mc}}$ values above $600{ }^{\circ} \mathrm{C}$ are taken from ref.(18) and extrapolated to room temperature. $\mathrm{C}_{\mathrm{o}}$ is calculated using Eq. 3 and 4. a and b parameters are the slope and intercept of oxygen nonstoichiometry data, $\delta$ and $\log \left(\mathrm{pO}_{2}\right)$ plot, respectively (28). The equation used for the ionic conductivity of CGO is: $1.095 \mathrm{e} 5$. $\exp \left(-\frac{0.64}{\mathrm{kT}}\right) / \mathrm{T}$ where $\mathrm{k}$ is the Boltzman constant $\left(\mathrm{JK}^{-1}\right)$ and $\mathrm{T}$ is the temperature $(\mathrm{K})$. The parameters used in the model can be found in Table III.

$$
\begin{gathered}
\gamma=\frac{1}{2}\left|\frac{\partial \ln p_{o 2}}{\partial \ln \delta}\right| \\
\mathrm{c}_{\mathrm{O}}=\frac{3-\delta}{3} \mathrm{c}_{\mathrm{mc}} \\
\mathrm{c}_{\mathrm{O}}\left(\mathrm{T}, \mathrm{P}_{\mathrm{O} 2}\right)=\mathrm{a}(\mathrm{T}) * \log \left(\mathrm{p}_{\mathrm{O} 2}\right)+\mathrm{b}(\mathrm{T})
\end{gathered}
$$

TABLE III. Parameters used in the ALS and 3D FEM model.

\begin{tabular}{cccccccc}
\hline Temp., ${ }^{\mathbf{C}} \mathbf{C}$ & $\begin{array}{c}\mathbf{C}_{\mathbf{m c}}, \\
\mathbf{m o l . m}^{-3}\end{array}$ & $\begin{array}{c}\mathbf{C}_{\mathbf{o}}, \\
\mathbf{m o l}_{\mathbf{m}} \mathbf{m}^{-\mathbf{3}}\end{array}$ & $\boldsymbol{\gamma}$ & $\mathbf{a ( T )}$ & $\mathbf{b}(\mathbf{T})$ & $\mathbf{D}^{\boldsymbol{\delta}}, \mathbf{m}^{\mathbf{2}} \mathbf{s}^{-\mathbf{1}}$ & $\mathbf{k}^{\mathbf{\delta}}, \mathbf{m}^{-\mathbf{1}}$ \\
\hline 550 & 85506 & 85075 & 448.33 & 218.47 & 85221 & $1.03 \mathrm{E}-15$ & $4.71 \mathrm{E}-07$ \\
600 & 85399 & 84937 & 410.00 & 238.08 & 85097 & $4.49 \mathrm{E}-15$ & $1.04 \mathrm{E}-06$ \\
650 & 85152 & 84773 & 378.75 & 257.69 & 84947 & $1.66 \mathrm{E}-14$ & $2.10 \mathrm{E}-06$ \\
\hline
\end{tabular}

The comparison of $\mathrm{ASR}_{\text {chem }}$ calculated by these two models can be found in Table IV. The results are in good agreement and thus validating the 3D FEM model. 


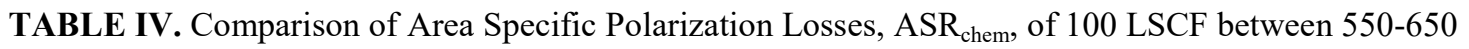
${ }^{\circ} \mathrm{C}$ by 1D ALS Model and 3D FEM Model.

\begin{tabular}{lccc}
\hline Model type & $\mathbf{6 5 0}^{\circ} \mathbf{C}$ & $\mathbf{6 0 0}^{\circ} \mathbf{C}$ & $\mathbf{5 5 0}^{\circ} \mathbf{C}$ \\
\hline 1D ALS & 0.040 & 0.111 & 0.353 \\
3D FEM model & $0.041 \pm 0.003$ & $0.121 \pm 0.007$ & $0.393 \pm 0.020$ \\
\hline
\end{tabular}

3D FEM Model Application to the Columnar Microstructure for Pure LSCF and for the Composite. Two cube-models representing a pure LSCF and a composite cathode with a columnar microstructure are generated including 15 vol. \% macro-pore channels and surface exchange on all sides of the column are activated. Making use of the symmetry, a quarter of $8 \times 8 \times 10 \mu \mathrm{m}^{3}$ columns were generated as shown in Figure .
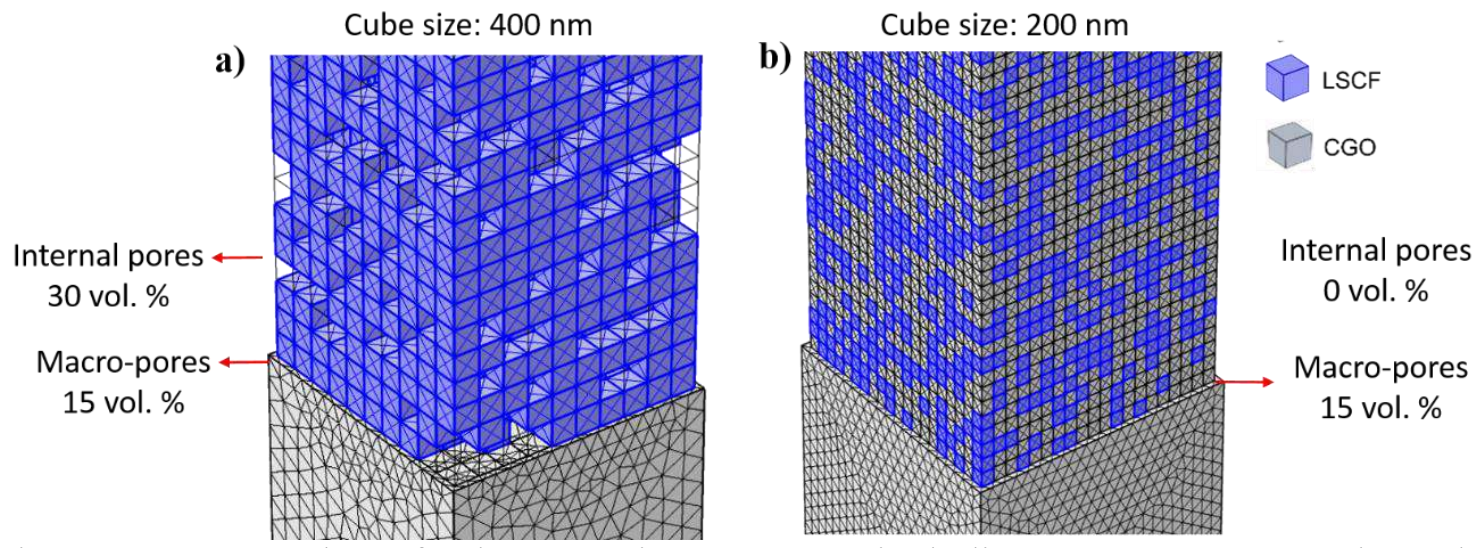

Figure 5. FEM meshes of columnar microstructures including 15\% macro-pore channels. a) 100 vol. $\%$ LSCF with 30 vol. \% internal porosity b) 60:40 vol. \% LSCF:CGO composite without any porosity within the column.

After assigning the porosity, $40 \%$ of the remaining cubes are assigned to CGO phase to represent 60:40 LSCF:CGO composite (Figure b). Taking into account the particle size ratio observed in the SEM images, a twice as high cube size (400 nm, LSCF) is selected for the pure LSCF (200 nm, composite). An estimate of $30 \%$ internal porosity for pure LSCF and a completely dense composite are used.

TABLE V. Average Area Specific Polarization Losses, ASR $_{\text {chem }}$, between $550-650{ }^{\circ} \mathrm{C}$ Obtained from 3D FEM.

\begin{tabular}{lccc}
\hline Sample & $\mathbf{6 5 0}^{\circ} \mathbf{C}$ & $\mathbf{6 0 0}^{\circ} \mathbf{C}$ & $\mathbf{5 5 0}^{\circ} \mathbf{C}$ \\
\hline 100 LSCF & 0.04 & 0.13 & 0.43 \\
60:40 LSCF:CGO & 0.05 & 0.09 & 0.19 \\
\hline
\end{tabular}

Table $\mathrm{V}$ shows the results of the 3D FEM simulations for 100 LSCF and 60:40 LSCF:CGO for a given microstructural property. $\mathrm{ASR}_{\text {chem }}$ of the composite is slightly higher than pure LSCF at $650{ }^{\circ} \mathrm{C}$ revealing that the composite may not be beneficial at high temperatures due to the micro/nano-structural evolution related to CGO addition (loss of the nano-porosity within the columns). However, in contradiction with our experimental observations, the model shows superior performance for the composite at temperatures lower than $600{ }^{\circ} \mathrm{C}$. Still, the correct trend is captured: as in the experiment, the $\mathrm{ASR}_{\text {chem }}$ increases slower for the composite as the operation temperature decreases. The observed overestimation of $\mathrm{ASR}_{\text {chem }}$ for pure LSCF sample may be related to the selection of the pore size ( $400 \mathrm{~nm}$ in model) leading to an underestimation of the specific 
surface area. Some controversy exists in the literature regarding the temperature regime at which the composite would actually be beneficial. Esquirol et al. experimentally observed a significant advantage of composite only below $500{ }^{\circ} \mathrm{C}(6)$. On the contrary, Søgaard et al. showed that the composite should be beneficial already at $600{ }^{\circ} \mathrm{C}$ in their 1D micro-scale model (16). The preliminary modelling results in this work reveal the composite superiority already at $600{ }^{\circ} \mathrm{C}$ regardless of the porosity. Nevertheless, the first obtained pilot results are promising and form the basis for further evaluation. A model of the electrode performance taking into account more detailed information on its geometry such as pore phase distribution/connectivity and active specific surface area is in progress. Besides, diffusion of oxygen gas through the pores will be added. We believe that this is an important parameter to distinguish the porosity related electrode performance.

\section{Conclusions}

The effect of micro/nano-structural changes on the cathode performance in terms of $\mathrm{ASR}_{\text {chem }}$ has been studied. A functional layer of pure LSCF and 60:40 LSCF:CGO composite were deposited by ESD, followed by a current collecting layer of LSCF by SP technique. The addition of CGO resulted in the densification of the ESD film with smaller particle sizes. Electrochemical impedance measurements revealed exceptionally low ASR values of 0.02 and $0.06 \Omega \mathrm{cm}^{2}$ for pure LSCF at 650 and $600{ }^{\circ} \mathrm{C}$, respectively. In contrast with the results reported in the literature, values almost twice as high were measured for the composite at these temperatures. Since existing 1D models cannot be applied on an inhomogeneous microstructure or a composite cathode, we have considered 3D FEM modelling. In order to simulate and compare the effect of the geometry on the electrode performance of pure and composite cathodes, a previously established 3D cubic particle model is adapted to model columnar microstructures. The validity of the 3D FEM model is ensured by comparing $\mathrm{ASR}_{\text {chem }}$ of a macrohomogeneous LSCF cathode with the analytical solution of 1D ALS model. Numerical calculations of ASR depending on the microstructural parameters, chemical composition and temperature have been conducted on a columnar microstructure including 15 vol. \% macro-pore channels. Despite the lack of real microstructural parameters, the model predicted close values for both films at 650 ${ }^{\circ} \mathrm{C}$. This model is adaptable to any type of cathode geometry. Implementing real geometrical parameters including gas diffusion within the columns is planned.

\section{Acknowledgments}

This work was performed within the framework of the Centre of Excellence of Multifunctional Architectured Materials "CEMAM" $\mathrm{n}^{\circ}$ AN-10-LABX-44-01. The authors wish to thank Elisabeth Siebert for valuable discussion.

\section{References}

1. M. Sahibzada, B. C. H. Steele, K. Zheng, R. A. Rudkin, and I. S. Metcalfeb, Catal. Today, 38, 459-466 (1997).

2. S. B. Adler, Chem. Rev., 104, 4791-843 (2004).

3. J. W. Stevenson, T. R. Armstrong, R. D. Carneim, L. R. Pederson, and W. J. 
Weber, J. Electrochem. Soc., 143, 2722-2729 (1996).

4. L. W. Tai, M. M. Nasrallah, H. U. Anderson, D. M. Sparlin, and S. R. Sehlin, Solid State Ionics, 76, 273-283 (1995).

5. S. B. Adler, J. A. Lane, and B. C. H. Steele, J. Electrochem. Soc., 143, 3554 3564 (1996).

6. A. Esquirol, J. Kilner, and N. Brandon, Solid State Ionics, 175, 63-67 (2004).

7. V. Dusastre and J. A. Kilner, Solid State Ionics, 126, 163-174 (1999).

8. E. P. Murray, M. J. Sever, and S. A. Barnett, Solid State Ionics, 148, 27-34 (2002).

9. H. J. Hwang, J.-W. J. W. Moon, S. Lee, and E. A. Lee, J. Power Sources, 145, 243-248 (2005).

10. Y. Leng, S. Chan, and Q. Liu, Int. J. Hydrogen Energy, 33, 3808-3817 (2008).

11. D. Beckel, U. Muecke, T. Gyger, G. Florey, A. Infortuna, and L. Gauckler, Solid State Ionics, 178, 407-415 (2007).

12. D. Marinha, J. Hayd, L. Dessemond, E. Ivers-Tiffée, and E. Djurado, J. Power Sources, 196, 5084-5090 (2011).

13. C.-S. S. Hsu, B.-H. H. Hwang, Y. Xie, and X. Zhang, J. Electrochem. Soc., 155, B1240 (2008).

14. I. Taniguchi, R. C. van Landschoot, and J. Schoonman, Solid State Ionics, 160, 271-279 (2003).

15. D. Marinha, L. Dessemond, J. S. Cronin, J. R. Wilson, S. A. Barnett, and E. Djurado, Chem. Mater., 23, 5340-5348 (2011).

16. M. Søgaard, P. V. Hendriksen, T. Jacobsen, and M. Mogensen, 7th Eur. SOFC Forum, B064 (2006).

17. B. Ruger, A. Weber, and E. Ivers-Tiffée, ECS Trans., 7, 2065 (2007).

18. T. Carraro, J. Joos, B. Rüger, A. Weber, and E. Ivers-Tiffée, Electrochim. Acta, 77, 315-323 (2012).

19. . D. Marinha, C. Rossignol, and E. Djurado, J. Solid State Chem., 182, 1742-1748 (2009).

20. L. Dieterle, P. Bockstaller, D. Gerthsen, J. Hayd, E. Ivers-Tiffée, and U. Guntow, Adv. Energy Mater., 1, 249-258 (2011).

21. K. Huang, J. Electrochem. Soc., 151, H117 (2004).

22. S. P. Yoon, S. W. Nam, S. G. Kim, S. A. Hong, and S. H. Hyun, J. Power Sources, 115, 27-34 (2003).

23. . D. Marinha, L. Dessemond, and E. Djurado, J. Power Sources, 197, 80-87 (2012).

24. S. J. Cooper, M. Kishimoto, F. Tariq, R. S. Bradley, A. J. Marquis, N. P. Brandon, J. A. Kilner, and P. R. Shearing, ECS Trans., 57, 2671-2678 (2013).

25. J. Laurencin, R. Quey, G. Delette, H. Suhonen, P. Cloetens, and P. Bleuet, J. Power Sources, 198, 182-189 (2012).

26. J. Joos, T. Carraro, A. Weber, and E. Ivers-Tiffée, J. Power Sources, 196, 73027307 (2011).

27. J. R. Wilson, W. Kobsiriphat, R. Mendoza, H. Y. Chen, J. M. Hiller, D. J. Miller, et al., Nat. Mater., 5, 541-4 (2006).

28. H. J. M. Bouwmeester, M. W. Den Otter, and B. A. Boukamp, J. Solid State Electrochem., 8, 599-605 (2004).

29. S. N. Lee, PhD. Thesis, Imperial College London (2014).

30. M. Katsuki, S. S. Wang, M. Dokiya, and T. Hashimoto, Solid State Ionics, 156, 453-461 (2003).

31. B. C. H. Steele and J. Bae, Solid State Ionics, 106, 255-261 (1998). 